\title{
COVID-19: breve análise dos impactos ambientais causados pela pandemia
}

COVID-19: brief analysis of the environmental impacts caused by the pandemic

COVID-19: breve análisis de los impactos ambientales causados por la pandemia

\author{
Aline Costa de Albuquerque \\ Graduanda, FACIMED, Brasil \\ alibarics@hotmail.com \\ Nadine Lessa Figueredo Campos \\ Professora Mestre, FACIMED, Brasil \\ nadine_lessa@hotmail.com \\ Fernanda Cavatti Simioni \\ Professora Mestre, FACIMED, Brasil \\ nandacavatti@hotmail.com
}




\section{Revista Científica ANAP Brasil}

ISSN 1984-3240 - Volume 13, número 30, 2020

\section{INTRODUÇÃO}

Em dezembro de 2019 foi descoberto na cidade de Wuhan na China, o novo coronavírus, nomeado pela Organização Mundial de Saúde como covid-19. Com grande impacto mundial, a pandemia tem forçado a redução das atividades econômicas nas cidades mais afetadas, e as consequências ambientais causadas pela redução no funcionamento das indústrias e transportes estão sendo estudados por cientistas e instituições em todo o globo.

De acordo com a publicação do site Futurity (2020, tradução nossa), "o covid-19 é um 'experimento global' para o meio ambiente e os pesquisadores estão correndo para coletar dados para avaliar modelos climáticos e determinar o real impacto do coronavírus no meio ambiente e na saúde humana". Mas, para determinar com confiança como e porque as emissões de gases de efeito estufa estão mudando devido aos impactos sociais e econômicos causados pelo covid-19, acredita-se que os pesquisadores precisam de meses de monitoramento, além de vários tipos de medição e modelos sofisticados de computadores.

Desta forma, segundo a Nasa (2020, tradução nossa), os cientistas já estão usando informações dos satélites de observações da Terra, sensores no solo e um conjunto de dados baseados em computador para estudar os impactos ambientais, econômicos e sociais do covid-19. Apesar de existirem alguns pesquisadores que acreditem que após o fim da quarentena tudo volte ao normal, outros acreditam que se encontrarem um elo concreto entre esses impactos e o covid19 , pode-se mudar a forma de pensar sobre o meio ambiente futuramente, melhorando questões como mobilidade urbana para evitar altos índices de poluentes nas cidades.

Para Pscheidt (2020), "o novo coronavírus se alastrou pelo mundo graças à ação destrutiva e invasora do ser humano contra a natureza". Para o cientista, o vírus já está há muito tempo no meio ambiente, no entanto, com a globalização, "o vírus quebrou seu ciclo natural e alcançou outros seres, como o homem, cujo organismo ainda não está preparado para combatê-lo".

Em suma, com a expansão do contágio, os países vêm aplicando medidas de segurança para conter a pandemia, o isolamento social e a redução das atividades comerciais e industriais são exemplos das medidas adotadas durante a quarentena. Com as indústrias, transportes e comércios fechados, surgem os efeitos ambientais causados por estas medidas, principalmente em países mais desenvolvidos.

\section{OBJETIVOS}

O objetivo deste estudo é compreender e verificar os impactos causados no meio ambiente pelo Covid-19 com a desaceleração da rotina industrial e comercial. Quanto aos objetivos específicos, faz-se necessário analisar como as medidas de isolamento estão influenciando no meio ambiente e na atmosfera, apresentando os índices de redução da poluição atmosférica por dióxido de carbono (CO2) e dióxido de nitrogênio (NO2), principais poluentes emitidos pelos veículos automotores e instalações industriais, e assim, conscientizar sobre os impactos diários causados pelo homem ao meio ambiente e estimular novos hábitos pós pandemia: deslocamentos menores, mais racionalidade e mais sustentabilidade.

\section{METODOLOGIA / MÉTODO DE ANÁLISE}

Este estudo baseia-se no método de pesquisa bibliográfica e documental, pois apesar de ser um assunto em pauta em vários âmbitos mundiais, ainda precisa de muitas respostas tanto em 


\title{
Revista Científica ANAP Brasil
}

\author{
ISSN 1984-3240 - Volume 13, número 30, 2020
}

relação ao covid-19 quanto aos seus reais impactos positivos. Segundo Gil (2008) "a pesquisa documental vale-se de materiais que não receberam ainda um tratamento analítico, ou que ainda podem ser reelaborados de acordo com os objetivos da pesquisa".

Portanto, as informações apresentadas serão coletadas por meio de documentários, artigos de jornais, revistas, entrevistas e fotografias, disponíveis em plataformas digitais. Os descritores aplicados foram "coronavírus + meio ambiente" e "impactos positivos + covid-19".

\section{RESULTADOS}

Nos Estados Unidos, o tráfego de veículos em estradas e rodovias caiu drasticamente no momento em que o governou implantou a quarentena no país, esta ação resultou na imediata redução da poluição do ar.

Os dados do satélite do Sentinel-5P processados pelo Descartes Labs que detecta as emissões de gases na atmosfera (Figura 1), principalmente os produzidos por veículos, apresenta quedas de poluição nas principais áreas metropolitanas, incluindo Los Angeles, Seattle, Nova York, Chicago e Atlanta (PLUMER; POPOVICH, 2020, tradução nossa).

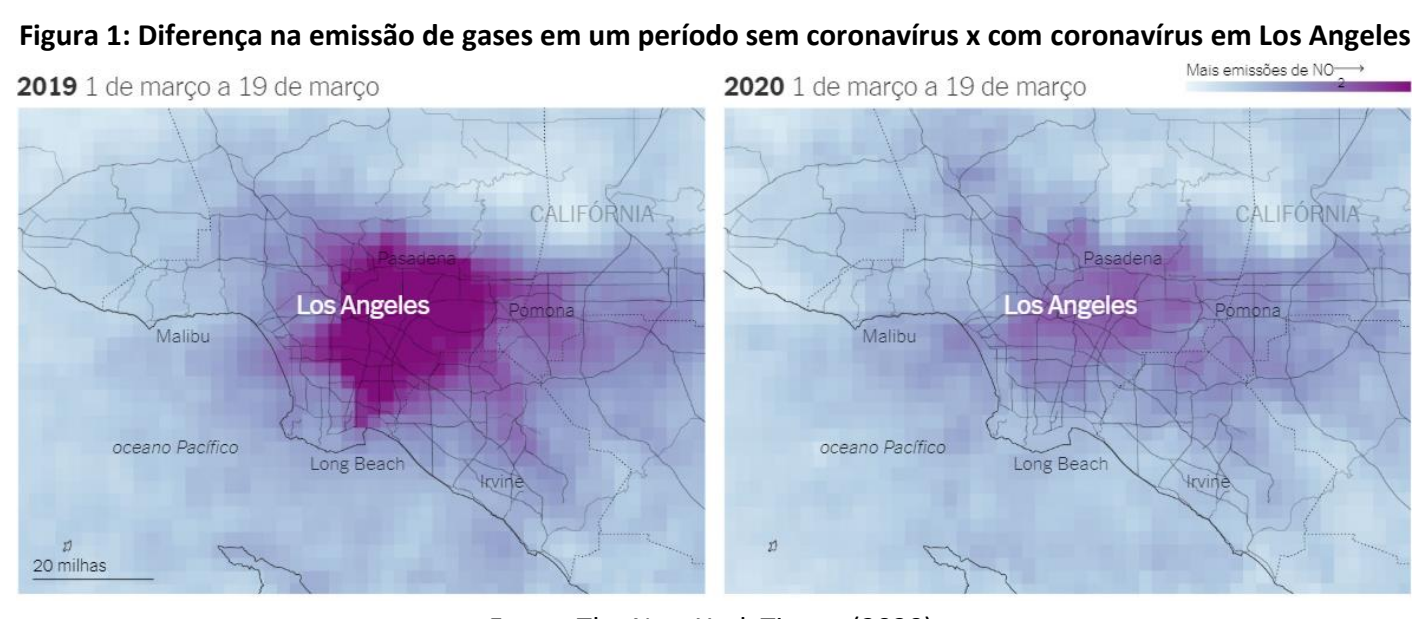

Fonte: The New York Times. (2020).

Vale ressaltar, que Los Angeles é uma cidade dependente de veículos e que normalmente apresenta um dos maiores índices de poluição atmosférica dos Estados Unidos. Com o isolamento social, empresas e escolas tiverem de ser fechadas, o que contribuiu para a diminuição de engarrafamentos e consequentemente para redução dos níveis de dióxido de nitrogênio na atmosfera.

Em Nova York, grande parte da população local utiliza o transporte público como meio de locomoção, no entanto, segundo Plumer e Popovich (2020, tradução nossa), dados apresentados por pesquisadores da Universidade de Columbia, mostram que as emissões de monóxido de carbono também reduziram em mais de $50 \%$ em comparação ao ano anterior, por estar associada à queda no tráfego de veículos na cidade. A figura abaixo, apresenta uma comparação dos níveis de NO2 em Nova York, em março de 2019 e março de 2020. 
Figura 2: Emissão de gases antes e depois do coronavírus em Nova York
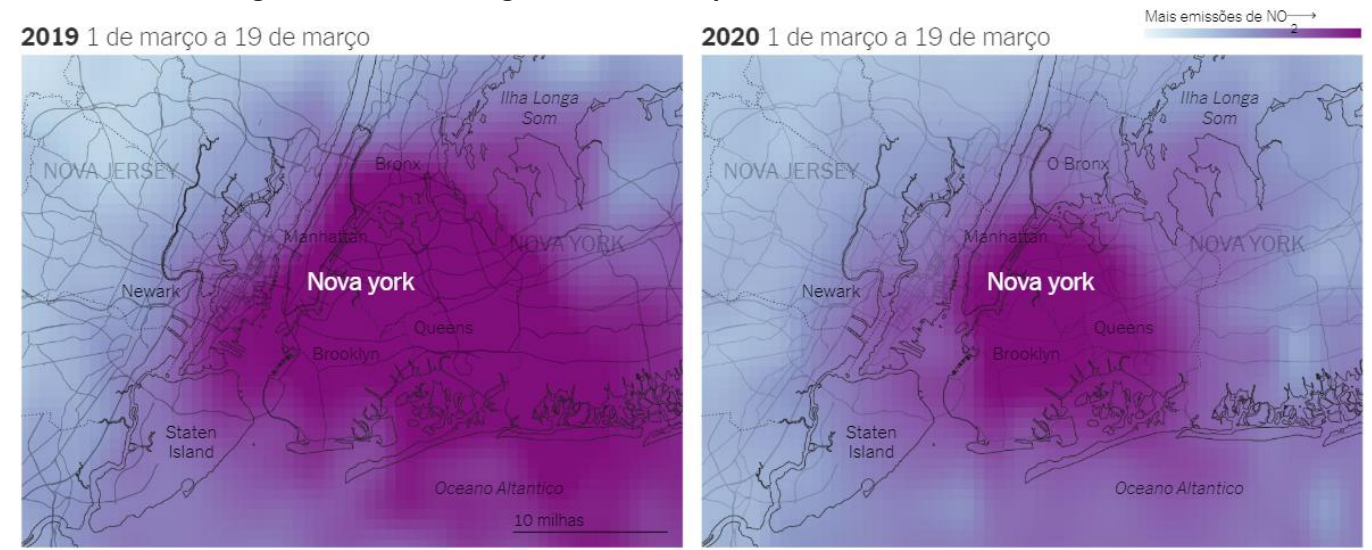

Fonte: dados de satélite do Sentinel-5P processados pelo Descartes Labs, apresentado pelo The New York Times.

No Brasil, os grandes centros como São Paulo, Rio de Janeiro, Brasília, Goiânia, Curitiba, Salvador e Belo Horizonte, também tiveram aspectos positivos a serem levados em consideração em relação a diminuição nos níveis de poluição do ar.

Em São Paulo, por exemplo, por ser a cidade brasileira que mais sofre com o aumento do número de casos do Covid-19, a imposição do isolamento social contribuiu para reduzir em $50 \%$ o índice de poluentes.

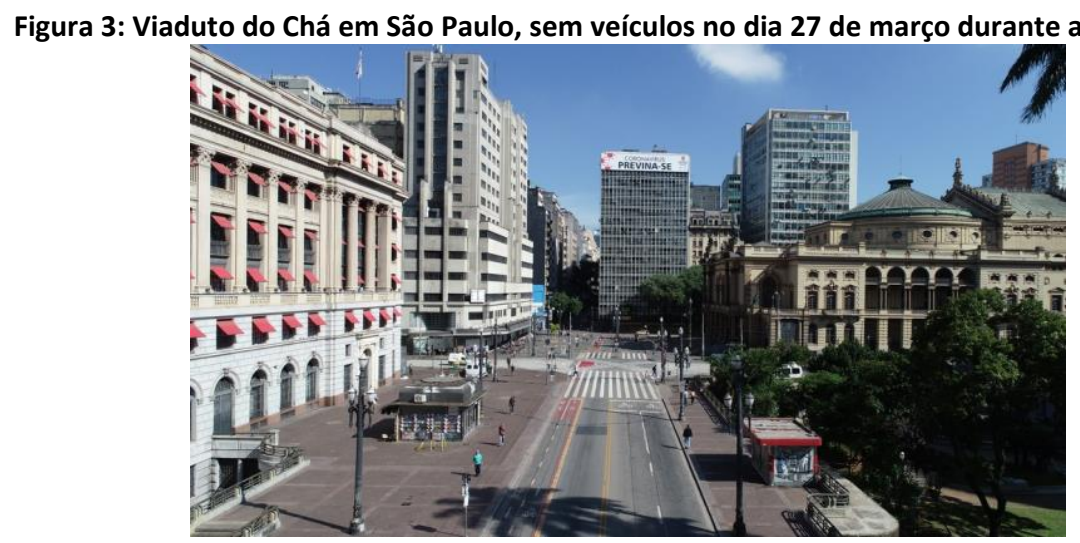

Fonte: Giaccomo Voccio/G1. (2020).

Vale ressaltar, que a principal fonte de emissão de poluentes em São Paulo é a frota veicular, sendo a região central com maior notoriedade sobre essas mudanças. De acordo com dados obtidos pelo G1 (2020), durante o período da pandemia o índice de poluentes que desencadeiam doenças respiratórias diminuiu em cerca de $30 \%$.

\section{CONCLUSÃO}

As atividades irracionais do ser humano são o maior problema do planeta e consequentemente dos altos níveis de poluição. Contudo, a pandemia do Covid-19 tem comprovado cada vez mais isso.

Pode-se notar que de fato, o coronavírus tem impacto positivo no meio ambiente, e com o isolamento, os lugares que se atingiam grandes níveis de poluição do ar, atualmente contemplam um céu mais limpo e o ar mais puro. 


\section{Revista Científica ANAP Brasil}

ISSN 1984-3240 - Volume 13, número 30, 2020

Apesar dos cientistas acreditarem que com a diminuição do surto do novo coronavírus e com a rotina diária das pessoas se normalizando a poluição volte a se estabilizar da forma que era antes, é um momento de refletirmos sobre a qualidade de vida atual e principalmente sobre o meio ambiente, buscando adquirir novos hábitos e estabelecendo novos costumes nas rotinas diárias que contribuam sobretudo para preservação ambiental.

\section{REFERÊNCIAS BIBLIOGRÁFICAS}

FUTURITY. Covid-19 is a 'global experiment' for the environment. FUTURITY, 24 abr. 2020. Disponível em: https://www.futurity.org/covid-19-pandemic-environment-2347422-2/. Acesso em: 02 maio 2020.

G1 GLOBO. Poluição do ar em São Paulo diminui 50\% na primeira semana de quarentena. G1 SP, São Paulo, 08 abr. 2020. Notícia. Disponível em: https://g1.globo.com/sp/sao-paulo/noticia/2020/04/08/poluicao-do-ar-em-saopaulo-diminui-50percent-na-primeira-semana-de-quarentena.ghtml. Acesso em: 28 abr. 2020.

GIL, Antonio Carlos. Métodos e Técnicas de Pesquisa Social. 6 ed. São Paulo: Editora Atlas S.A, 2008. 220 p. Disponível em: https://ayanrafael.files.wordpress.com/2011/08/gil-a-c-mc3a9todos-e-tc3a9cnicas-de-pesquisasocial.pdf. Acesso em: 26 mar. 2020.

MINISTÉRIO DA SAÚDE. Sobre a doença. Disponível em: https://coronavirus.saude.gov.br/sobre-a-doenca\#o-que-ecovid. Acesso em: 28 abr. 2020.

NASA. NASA Probes Environment, COVID-19 Impacts, Possible Links. NASA, 29 abr. 2020. Característica. Disponível em: https://www.nasa.gov/feature/nasa-probes-environment-covid-19-impacts-possible-links. Acesso em: 02 maio 2020.

PLUMER, Brad; POPOVICH, Nadja. Traffic and Pollution Plummet as U.S. Cities Shut Down for Coronavirus. The New York Times, 22 mar. 2020. Clima. Disponível em:

https://www.nytimes.com/interactive/2020/03/22/climate/coronavirus-usa-traffic.html. Acesso em: 28 mar. 2020.

PSCHEIDT, Allan Carlos. Ação humana contra o meio ambiente causou a pandemia do coronavírus, diz pesquisador. Entrevista concedida a Erick Gimenes. Brasil de Fato, Brasília (DF), 18 mar. 2020. Disponível em: https://www.brasildefato.com.br/2020/03/18/acao-humana-contra-o-meio-ambiente-causou-a-pandemia-docoronavirus-diz-pesquisador. Acesso em: 24 abr. 2020. 